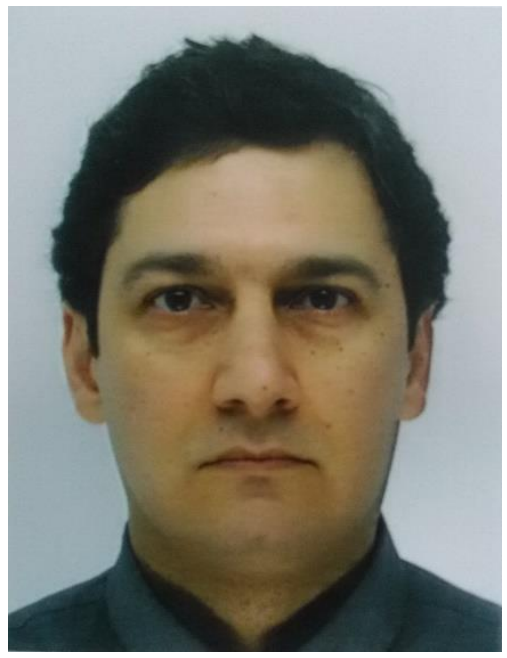

\title{
Energy Consumption and Transportation in Developing Countries: Need for Local Scenario- Based Energy Efficiency Plans
}

\author{
Assoc. Prof. Dr. Houshmand Masoumi ${ }^{12}$ \\ 1 Senior Researcher, Center for Technology and Society, Technische \\ Universität Berlin, Germany. \\ 2 Visiting Associate Professor, Department of Transport and Supply Chain \\ Management, University of Johannesburg, South Africa. \\ Email : masoumi@ztg.tu-berlin.de
}

Like several other sub-topics of urban planning and mobility research, research on the impacts of (urban) transportation on energy consumption is mainly based on the outcomes of studies on high-income and often Western countries. Developing countries and emerging markets have a smaller share of the international research on the topic, while policymaking based on local empirical research, they could cut a percentage of unnecessary energy overuse. The benefits of policymaking based on empirical transportation / energy research do not remain limited to energy efficiency; it also has positive effects on environmental pollution control. Moreover, transportation [1] and urban planning [2,3,4] policies can limit both energy use and air pollution, however such efficiency improvements may be most effective when they are derived from the vernacular conditions. This is important because the energy consumption of the transportation sector is rapidly increasing. In a country as populated and large as China, the oil consumed by transportation corresponded to $49.6 \%$ of oil use in the whole country in 2006 [5], while the results of a study undertaken only four years later shows that $60.1 \%$ of the Chinese petroleum end-use is caused by transportation [6]. Out of the large part of overall energy use share caused by transportation sector, private cars are important users. In Mexico, private vehicles account for $31 \%$ of transport energy consumption [7]. The Chinese energy consumption and CO2 emission conditions need further improvements in the transportation sector [8].

The conditions are the same in several other comparable countries. Even though studies on developing countries and emerging markets are not comparable to those of high-income countries, still a few studies have been conducted on the relations between urban transportation and energy consumption in these geographical contexts. For instance, it has been shown that renewable energy use Granger-cause energy consumption in road transportation in Malaysia [9]. There is a unidirectional causality from transport infrastructure to energy consumption in India [10]. Furthermore, there is a bidirectional causality between transport energy consumption, FDI and CO2 emissions in Thailand and Malaysia [11]. Nevertheless, a causal relationship between transport energy use and all environmental emissions has not been found, e.g. in Pakistan no evidence for the role of transport energy consumption on $\mathrm{CO} 2$ emission has been recognized [12].

In many developing countries, fast urbanization is related to transportation energy use. The reason lies in the close relationship between urbanization and urban sprawl on the one hand and motorization rate and traffic generation on the other hand. Although many years ago it has been observed in several international cities that urban densities are positively correlated with transport energy consumption [13,14], it has also been shown that this relation exists only on the urban level. On a regional level, this relation is weak, as it has been shown in certain regions of Iran [15]. In Tunisia, vehicle fuel intensity, vehicle intensity, GDP per capita, urbanized kilometers and national road network were the main causes of transport energy consumption between 1990 and 2006 [16]. In China, the road transportation energy 
consumption rises by 1.26 percentage points for every percent increase in urbanization [17], hence changing urban morphology can theoretically result in different urban transport energy consumption [18]. The association of urbanization and energy consumption is unsurprising, as urban growth and development is an essential attribute of economic growth. A recent empirical study on the countries of the Middle East and North Africa (MENA) countries confirms the existence of associations of transport energy consumption and transport infrastructure with economic growth [19].

The overall conclusion of this editorial note is that although the number of recent studies on the connections of transportation and energy use in developing countries and emerging markets may look considerable, it is still not consistent and comprehensive because the mentioned studies are only considerable in number when they are accounted as a whole, as well as being focused generally on a very large geographical and cultural context. However, when investigating the smaller-scale correlation between transportation and energy use, it becomes clear that the number of reliable empirical studies in each country do not provide consistent and usable results for policymaking. The example of such studies have been produced for example on India, the results of which shows that "if rail could capture $50 \%$ modal share in the years 2005-2006 and 2020-2021, it would save nearly 35\% energy consumption and emissions compared to the situation when existing patterns of modal split are allowed to continue without policy intervention." [20]. In the example above, policymakers have received recommendations for controlling energy use and emissions based on scenario planning using the data and conditions of the local context, but the number of such studies are not enough for a population of 1.35 billion inhabitants accommodated in a wide cultural and geographical diversity. Another example of energy consumption reduction strategies based on urban transportation local scenario planning, which many developing countries need, has been done on Beijing, the results of which necessitates development of public transport in order to gain energy savings and emission reductions [21]. Finally, the third example is on Greater Cairo, where impact assessment was undertaken applying the energy efficiency and greenhouse gases reduction scenario with the assumption of "metro did not exist" for the time period of 1987-2001. In conclusion, still much more research is needed to facilitate policymaking in countries listed as developing countries and emerging markets based on local data, analyses, and scenario planning.

\section{References}

[1] P. Poudenx. The effect of transportation policies on energy consumption and greenhouse gas emission from urban passenger transportation. Transportation Research Part A: Policy and Practice, 2008, Vol. 42, Issue 6, pp. 901-9. https://doi.org/10.1016/i.tra.2008.01.013

[2] M. Breheny. The compact city and transport energy consumption. Transactions of the institute of British Geographers, 1995, pp. 81-101.

[3] O. Mindali, A. Raveh, and I. Salomon. Urban density and energy consumption: a new look at old statistics. Transportation Research Part A: Policy and Practice, 2004, Vol. 38, Issue 2, pp. 143-62. https://doi.org/10.1016/j.tra.2003.10.004

[4] R. Hickman and D. Banister. Transport and reduced energy consumption: what role can urban planning play?, Transport Studies Unit, University of Oxford, 2007.

[5] M. Zhang, H. Li, M. Zhou, and H. Mu. Decomposition analysis of energy consumption in Chinese transportation sector. Applied Energy, 2011, Vol. 88, Issue 6, pp. 2279-85. https://doi.org/10.1016/j.apenergy.2010.12.077

[6] J. I. Shunping, M. A. Baohua, L. I. Shuang, and S. U. Qipeng. Calculation and analysis of transportation energy consumption level in China. Journal of Transportation Systems Engineering and Information Technology, 2010, Vol. 10, Issue 1, pp. 22-7. https://doi.org/10.1016/S1570-6672(09)60020-9

[7] J. C. Solís, C. Sheinbaum. Energy consumption and greenhouse gas emission trends in Mexican road transport. Energy for Sustainable Development, 2013, Vol.17, Issue 3, pp. 280-7. https://doi.org/10.1016/i.esd.2012.12.001

[8] X. Yin, W. Chen, J. Eom, L. E. Clarke, S. H. Kim, P. L. Patel, S. Yu, G. and P. Kyle. China's transportation energy consumption and $\mathrm{CO} 2$ emissions from a global perspective, Energy Policy, Vol. 82, pp. 233-48. https://doi.org/10.1016/i.enpol.2015.03.021 
[9] A. A. Azlina, S. H. Law, and N. H. Mustapha. Dynamic linkages among transport energy consumption, income and CO2 emission in Malaysia, Energy Policy 2014. Vol. 73, pp. 598-606. https://doi.org/10.1016/i.enpol.2014.05.046

[10] R. P. Pradhan. Transport infrastructure, energy consumption and economic growth triangle in India: Cointegration and causality analysis. Journal of Sustainable Development, 2010, Vol. 3, Issue 2, pp. 167-173.

[11] V. G. Chandran, C. F. Tang. The impacts of transport energy consumption, foreign direct investment and income on $\mathrm{CO} 2$ emissions in ASEAN-5 economies. Renewable and Sustainable Energy Reviews, 2013 Vol. 24, pp. $445-$ 53. https://doi.org/10.1016/i.rser.2013.03.054

[12] M. A. Baloch. Dynamic linkages between road transport energy consumption, economic growth, and environmental quality: evidence from Pakistan. Environmental Science and Pollution Research, 2018, Vol. 25, Issue 8, pp. 7541-52. https://doi.org/10.1007/s11356-017-1072-1

[13] P. W. G. Newman, J. R. Kenworthy. Gasoline consumption and cities: a comparison of US cities with a global survey., Journal of American Planning Association, 1989, Vol. 55, pp. 24-37

[14] P. W. G. Newman, J. R. Kenworthy. Sustainability and cities: overcoming automobile dependence. Island, Massachusetts, 1999.

[15] H. E. Masoumi, H. Soltanzadeh. A regional analysis of urban population and transport energy consumption. International Journal for Traffic \& Transport Engineering, 2014, Vol. 4, Issue 4, pp. 372-385. http://dx.doi.org/10.7708/ijtte.2014.4(4).02

[16] R. Mraihi, K. ben Abdallah, and M. Abid. Road transport-related energy consumption: Analysis of driving factors in Tunisia, Energy Policy, 2013, Vol. 62, pp. 247-53. https://doi.org/10.1016/i.enpol.2013.07.007

[17] J. Chai, Q. Y. Lu, S. Y. Wang, K. K. Lai. Analysis of road transportation energy consumption demand in China. Transportation Research Part D: Transport and Environment, 2016, Vol. 48, pp. 112-24. https://doi.org/10.1016/j.trd.2016.08.009

[18] J. Zhou, J. Lin, S. Cui, Q. Qiu, and Q. Zhao. Exploring the relationship between urban transportation energy consumption and transition of settlement morphology: A case study on Xiamen Island, China. Habitat international, 2013, Vol. 37, pp. 70-9. https://doi.org/10.1016/j.habitatint.2011.12.008

[19] S. Saidi, M. Shahbaz, and P. Akhtar. The long-run relationships between transport energy consumption, transport infrastructure, and economic growth in MENA countries. Transportation Research Part A: Policy and Practice, 2018, Vol. 111, pp. 78-95. https://doi.org/10.1016/i.tra.2018.03.013

[20] R. Ramanathan. Estimating energy consumption of transport modes in India using DEA and application to energy and environmental policy. Journal of the Operational Research Society, 2005, Vol. 56, Issue 6, pp. 732-7. https://doi.org/10.1057/palgrave.jors.2601866

[21] X. Liu, S. Ma, J. Tian, N. Jia, G. Li. A system dynamics approach to scenario analysis for urban passenger transport energy consumption and CO2 emissions: A case study of Beijing. Energy Policy, 2015, Vol. 85, pp. 253-70. https://doi.org/10.1016/j.enpol.2015.06.007

\section{About Assoc. Prof. Dr. Houshmand Masoumi}

Assoc. Prof. Dr. Houshmand Masoumi is senior researcher at Technische Universität Berlin, Germany, and visiting associate professor at University of Johannesburg, South Africa. His research interest is urban transportation planning with a strong focus on statistical analysis of urban travel behavior including land use, socioeconomics, public health, and human perceptions. Until mid-2020, he published about 70 scientific publications, most of which peer-reviewed journal papers. 